\title{
PRECONCEITO CONTRA A MULHER NA EDUCAÇÃO FISICA ESCOLAR NO NONO ANO
}

\author{
PREJUDICE AGAINST OF WOMEN IN SCHOOL \\ PHYSICAL EDUCATION IN NINTH YEAR
}

\section{Marcelo Victor da Rosa}

Doutor em Educação pela Universidade Federal de Mato Grosso do Sul (Campo Grande/Brasil)

Professor do Programa de Pós-Graduação Mestrado em Estudos Culturais na Universidade Federal de Mato Grosso do Sul

(Aquidauana/Brasil)

E-mail: marcelo.rosa@ufms.br

\section{Marizete de Oliveira Souza}

Graduada em Licenciatura em Educação Física pela Universidade Federal de Mato Grosso do Sul (Campo Grande/Brasil)

E-mail: marizetecristo279@hotmail.com

\section{Andrey Monteiro Borges}

Mestre em Antropologia pela Universidade Federal de Mato Grosso do Sul (Campo Grande/Brasil)

E-mail: andreyedfisicaa@gmail.com

O presente trabalho foi realizado com apoio da Coordenação de Aperfeiçoamento de Pessoal de Nível Superior

- Brasil (CAPES) - Código de Financiamento 001

Recebido em: 20 de agosto de 2019

Aprovado em: 12 de novembro de 2019

Sistema de Avaliação: Double Blind Review

RPR |a. 17 | n. 1 | p. 102-117 |jan./abr. 2020

DOI: https://doi.org/10.25112/rpr.v1i0.1789 


\section{RESUMO}

Este presente artigo refere-se às formas de preconceito/discriminação contra mulheres alunas e professora nas aulas de Educação Física na turma do nono ano de uma Escola do Município de Camapuã/ MS. Tal pesquisa é de cunho qualitativo e teve como amostra o total de 20 alunos/as do $9^{\circ}$ (nono) ano do Ensino Fundamental, sendo 11 meninos e 09 meninas. Temos por objetivo analisar as manifestações de preconceito/discriminação para com as alunas e professora durante as aulas de Educação Física. Para a coleta de dados realizamos observações e os registros foram feitos em um diário de campo. Verificou-se que a prática das referidas aulas se dão de forma mista. Os dados da amostra evidenciam preconceito e discriminação por parte de alunos em relação à participação das meninas durante as aulas de Educação Física, inclusive em aceitar que as aulas de treinamento sejam ministradas por uma professora, pois, em suas concepções, a "professora" não tem domínio de futebol e não os deixa jogar como querem.

Palavras-chave: Preconceito. Gênero. Educação Física Escolar.

\section{ABSTRACT}

This article refers to the forms of prejudice / discrimination against women students and teacher in the classes of Physical Education in the class of the ninth year of a School of the Municipality of Camapuã/ MS. This research is qualitative and had as a sample the total of 20 students from the 9 th (ninth) year of Elementary School, of which 11 were boys and 9 were girls. We aim to analyze the manifestations of prejudice / discrimination, towards the students and teacher during the classes of Physical Education. For the data collection we made observations and the records were made in a field diary. It was verified that the practice of said classes occur in a mixed way. The data of the sample show prejudice and discrimination on the part of the students regarding the participation of the girls during the classes of Physical Education, including in accepting that the training classes are taught by a teacher and in their conceptions "teacher" does not have a soccer field and do not let them play as they wish.

Keywords: Prejudice. Gender. School Physical Education. 


\section{INTRODUÇão}

Mesmo vivendo em um período em que se discutem as questões referentes a gênero, os quais homens e mulheres possam ter seus direitos resguardados na sociedade, percebe-se ainda em diferentes âmbitos a presença do preconceito em relação à participação das mulheres em diversas atividades.

Na Educação Física Escolar ainda é recorrente presenciarmos cenas de preconceito em relação à participação de meninas em determinados conteúdos, como brincadeiras e esportes. É muito comum ainda ouvir o termo "de menino" "de menina" no que se refere às atividades praticadas em aula.

Comumente, enquanto ainda em campo, os meninos apresentavam aversão ou dificuldade em participarem de atividades junto com as meninas, em muitos casos pelo fato de entenderem que elas não sabiam, acreditavam assim que elas não entendiam de futebol. Buscando uma maneira de intervir nestas situações, a professora procurava dialogar com toda a turma explicando que todos/as ali estavam para aprender.

Nesse sentido, este artigo surge da necessidade enquanto professores e professora de Educação Física de pesquisar os preconceitos ainda dominantes nas aulas desta disciplina, bem como as estratégias adotadas pela escola e, principalmente dos/as professores/as de Educação Física no sentido de se empenharem para reverter tal quadro.

É imprescindivel que haja um trabalho de conscientização para que em uma aula de Educação Física Escolar o foco seja o aprendizado do/a aluno/a, sua interação com o meio, mediante diferentes práticas ligadas a cultura de movimento, sem que haja exclusão ou se permita atitudes preconceituosas no que se refere às relações sociais que perpassam por questões de gênero.

Desta forma, esta pesquisa tem por objetivo analisar as manifestações de preconceito/discriminação, para com as alunas e professora existentes durante as aulas de Educação Física da turma do nono ano do Ensino Fundamental, em uma Escola Pública Municipal em Camapuã/MS. Será observado se há algum tipo de preconceito dos meninos com as meninas e professora, além disso, observar quais medidas adotadas pela professora diante dos atos de preconceito/discriminação (caso existam).

Além disso, se há restrições com as alunas durante as realizações das atividades práticas, se a professora utiliza atividades diferenciadas, ou se a mesma realiza as aulas com os/as alunos/as desenvolvendo as atividades de maneira mista, se for dessa maneira, qual a aceitação por parte dos/as alunos/as. 


\section{GÊNERO: APROXIMAÇÕES TEÓRICAS}

Para Cláudia Bonfim (2012), a sociedade trata o gênero como algo "imposto" aos indivíduos, com normas e regras, que devem ser seguidas, ou seja, já não é considerado apenas o termo ser homem ou ser mulher. Havendo uma naturalização/essencialização do que é ser homem, ou melhor, no contexto sociocultural, todo/a aquele/a que decidir por optar por algo diferente, como profissão, maneira de se vestir ou opção sexual, com certeza irá sofrer algum tipo de preconceito das demais pessoas do seu círculo de vida.

Gênero é o que "determina" aquilo que culturalmente seriam características do ser "masculino" e do "feminino": forma física, anatomia, maneira de se vestir, falar, gesticular, enfim, as atitudes, os comportamentos, os valores e os interesses de cada gênero (lembrando que essas características são designadas pela sociedade culturalmente dominante). Essas diferenças são estabelecidas historicamente, de acordo com dada sociedade, e influenciadas por sua cultura. Portanto, elas representam uma categoria histórica e não são naturalmente determinadas. (BONFIM, 2012, p. 37).

Em relação à citação acima, entende se que o termo gênero sofre muita divergência em relação ao ser masculino e feminino, uma vez que na sociedade são "impostas" linguagens e regras a serem seguidas pelos indivíduos. A partir de características de homens mais valorativas, como por exemplo, discursos biológicos que vão legitimar a performance do homem em diversos contextos como mais fortes em contraposição as mulheres, causando assim uma superioridade e maior prestígio deles, afirmando que esses têm mais capacidades por serem mais fortes, ágeis e mais capazes de realizar tais atividades. Deixando assim a mulher sempre em nível mais baixo, o que as apontam como incapazes de realizarem atividades de suas escolhas e que se julguem capazes.

Nesse cenário, o/a professor/a de Educação Física, mediante conflitos que dizem respeito a gênero e sexualidade e principalmente por existirem nas escolas durante suas aulas vários tipos de discriminação dos meninos para com as meninas e que são pouco debatidos como: diminuição de capacidade, menor tempo destinado a elas durante a aula e na generificação das atividades desenvolvidas, surge refletirmos mais acerca desse cenário.

Com base em Vagner Prado et all (2016), cabe também aos/as professores/as terem diálogos com os/as alunos/os para que haja uma desconstrução desses processos normalizadores/naturalizantes. Levando para a escola, mais precisamente para as aulas de Educação Física, temas atuais que despertem nos/as alunos/as o interesse e a necessidade de problematizar os discursos e práticas normativas que são reiteradas nestes espaços educacionais. 
Isso nos demonstra o quanto as formas de praticar os preconceitos ainda, em muitas das vezes, são institucionalizadas, não reconhecidas e quando reconhecidas, não são levadas a sério a ponto de entendê-los como crimes contra as pessoas atingidas diretamente, como afirma Manoel Santos:

As aulas esportivistas com ênfase na competição vieram por acentuar as diferenças entre os sexos, e as classificações e exclusões passaram a ser inevitáveis. 0 sexo feminino, considerado "frágil", perdeu espaço para a "aptidão masculina" relacionada ao esporte $(2012$, p. 36).

Guacira Louro (2001, p. 72), afirma que: "Se em algumas áreas escolares a constituição da identidade de gênero parece, muitas vezes, ser feita através dos discursos implícitos, nas aulas de Educação Física esse processo é, geralmente mais explícito e evidente", podendo contribuir para a construção das feminilidades e masculinidades e para superação de preconceitos de gênero, como a prática de algumas atividades esportivas pelas mulheres, ou possibilitar diferentes tipos de violências.

Segundo Aurélio Holanda (2009), o preconceito tem vários significados, e pode aparecer em diversas áreas da sociedade, ou seja, existem muitas formas de ser preconceituoso/a. Diante disso, pode se afirmar que o preconceito existente nas escolas, mais precisamente nas aulas de Educação Física contra as alunas, ainda não foram superados. Como por exemplo, "elas não entendem de futebol", "não conseguem correr", e "se machucam fácil em atividades físicas".

Desta forma, temos que:

Preconceito é qualquer opinião ou sentimento, sem exame crítico, sentimento hostil, de intolerância, tem um cunho negativo, ruim e grosseiro. Podemos considerar o preconceito como uma atitude discriminatória, indica um conhecimento pejorativo de alguém, ou de um grupo social (HOLANDA, 2009, p. 1380).

Ao abordarmos o tema preconceito na Educação Física Escolar, deparamo-nos com um sério problema que abrange este meio. É extremamente difícil pensar em práticas pedagógicas inclusivas, pois o que existe hoje, geralmente são práticas excludentes e pautadas no preconceito em todas as suas formas, seja racial ou por qualquer tipo de diferença. Helena Altmann (1998, p. 103), comenta que:

Em geral as pesquisas que investigam o problema da participação da mulher no esporte e nas atividades físicas como forma de lazer focaliza a mulher adulta (...). Isso é uma pena não somente porque a adolescência é um período chave para o processo de socialização da mulher para o esporte e as atividades físicas, mas é também o período em que os conceitos de ser mulher e feminilidade são estabelecidos; esses fatores têm um grande impacto na configuração do comportamento futuro e no interesse da mulher pelo esporte e pelas atividades físicas como forma de lazer. 
Dessa forma, por um longo período histórico e social, as mulheres foram vítimas do preconceito, de atos de violência, os quais em determinadas sociedades ou comunidades prevalecem até hoje, embora tenhamos na atualidade leis que estabeleçam direito aos homens e mulheres, as quais contribuem muito para amenizar e erradicar ações de violência e preconceito contra as mesmas.

A participação das mulheres na cultura de movimento, tanto no esporte de lazer, educacional ou de rendimento merece nossa atenção e reconhecimento, pois nem sempre foram e ainda não são iguais as condições de acesso e participação, quando comparada aos homens. Nesse caso quando os estereótipos ou preconceitos de gênero atacam direta e individualmente as mulheres, ferindo-as psicologicamente, transformando em obstáculos e impedimentos para participação e progressão da mulher em qualquer terreno esportivo, estamos diante de um quadro de violência, neste caso violência de gênero, conforme Cristina Paim (2009).

De acordo com Luiz Bozi et all (2008), quando o assunto discutido é gênero, logo percebe-se que há grande esforço por parte das mulheres, em derrubar as barreiras do preconceito constituídas pela sociedade no decorrer do tempo, preconceito este que se alojou nos diversos fatores da vida das mulheres, como: sexual, comportamento, religião e profissional.

Na escola, mais especificamente na Educação Física Escolar ou em atividades de cunho esportivo, cabe ao profissional da área, sempre se atentar aos comportamentos dos/as alunos/as, verificando a existência ou não de atitudes violentas. 0 mesmo deve sempre atuar de forma a prevenir tais atitudes, estimulando atividades inclusivas, onde não ocorram privilégios de um/a ou outro/a aluno/a, independentemente do sexo, gênero, raça/etnia, religião, entre outros marcadores sociais da diferença embora possa sempre trabalhar a conscientização da existência das diferenças.

Segundo Marcio Zamboni (2014), marcadores sociais da diferença são sistemas de classificação que organizam a experiência ao identificar certos indivíduos com determinadas categorias sociais, como gênero, sexualidade, cor, classe, religião, geração e outros, assim é importante dizer que eles nunca aparecem de forma isolada, eles estão sempre articulados na experiência dos indivíduos, no discurso e na política.

Kimberle Crenshaw (2004) acredita que alguns marcadores, fatores de discriminação, devem ser estudados juntos, pois influenciam diretamente uns nos outros; um exemplo é dado no trabalho da própria autora sobre violências contra mulheres negras, no qual estuda raça, classe, gênero e sexualidade interseccionados.

Aos/as professores/as de Educação Física cabe sempre estimular mediante atividades o direito dos/ as alunos/as praticarem as mesmas atividades, considerando os limites e especificidades de ambos, sem necessidade de um ter domínio sobre o outro. 


\section{ASPECTOS METOdOLÓGICOS}

Esta pesquisa é de cunho qualitativo. De acordo com Hartmut Güinther (2006), a pesquisa qualitativa é uma ciência baseada em textos produzidos por meio de levantamento de dados durante sua realização. O conceito do indivíduo como objeto de estudo, leva em consideração sua bagagem histórica, social e cultural, bem como o meio que este se desenvolveu ou se formou.

A população investigada foi composta por uma turma de 20 alunos/as do $9^{\circ}$ ano matutino de uma Escola da Rede Pública Municipal, em Camapuã, MS, sendo 11 meninos e 09 meninas. Como técnica de coleta de dados foi utilizado a observação, durante 3 dias do mês de abril de 2018. Cada aula durava 50 minutos.

Para efetivar as observações se chegava à escola às 09h 10min, começava a observação descrevendo o início das aulas com a chamada e roda de conversa inicial da professora com os/as alunos/as. Logo íamos para a quadra onde eram realizadas as aulas práticas.

Nesse momento ocorriam as observações, utilizando como instrumento para coleta de dados um caderno de diário de campo, para fazer anotações que se julgavam necessárias dos itens de roteiro, do que acontecia nas aulas, ou seja, as atitudes, as maneiras de comportamento dos meninos junto com as meninas. Essa ação causou muita curiosidade nos/as alunos/as. No segundo dia, foi necessário fazer algumas perguntas aos/as alunos/as e no terceiro dia, questionamos a professora em relação ao comportamento dos/as alunos/as.

Nos três dias da observação, quando do término da aula, saíamos da quadra e acompanhávamos juntamente com a professora até a sala de aula e lá permanecíamos até o sinal e a chegada da próxima professora.

Utilizamos o sistema de numeração dos/as alunos/as, sem identificá-los/as, para descrevê-los/as e fazer as análises das situações. Observávamos de forma silenciosa todas as ações dos/as alunos/as.

Para analisar as formas de preconceito registradas durante as observações, norteamos tais dados a partir de alguns/as autores/as citados/as na revisão literária, e também em outros/as citados/as posteriormente. Para que as cenas preconceituosas acontecidas durante as aulas de Educação Física, em relação aos alunos contra as alunas e professora fossem investigadas, o tipo de análise que realizamos se constituiu a partir da categoria terórica de gênero fundamentada principalmente pelos estudos de gênero na educação a partir dos/as seguintes autores/as: Guacira Lopes Louro, Helena Altmann, Wagner Xavier Camargo e Silvana Vilodre Goellner. 


\section{ANÁLISE DOS DADOS}

Para iniciar a observação, chegamos meia hora antes do início da aula. Primeiramente fomos à sala da diretora a qual nos encaminhou para a coordenadora que nos conduziu até a professora.

Ao encontrar a professora de Educação Física, relembramos que a observação se tratava de identificar preconceito e discriminação vividos pelas meninas durante as aulas de Educação Física. Ela nos recebeu com muita tranquilidade, dizendo que teríamos todo apoio de sua parte durante a permanência em suas aulas.

Ás 09h20min iniciou a aula, seguimos para a sala juntamente com a professora, que nos apresentou para os/as alunos/as. Neste dia estavam presentes 9 meninas e 8 meninos, haviam faltado 3 meninos. Foi explicado aos alunos/as pela professora qual o motivo de nossa presença.

No primeiro dia a aula teve início com exercícios de alongamento e uma atividade de pega-pega para aquecimento. Durante essa atividade, houve um incidente, o aluno1 deixou a perna na frente da aluna 1 para derrubá-la, depois falou que a mesma havia caído porque é "mole" e "não sabe nem correr". A professora chamou a sua atenção, explicando que ele não deve tratar as meninas daquela forma.

De acordo com Mauro Betti e Luiz Zuliani (2002), a Educação Física originou-se há alguns séculos com a necessidade de conseguir preparar homens fisicamente para assumir os serviços militares e para disputar algum tipo de competição esportiva de alto rendimento, nas quais as mulheres eram rigidamente proibidas.

Ao chegar às escolas como disciplina, a Educação Física não teve muito espaço nem apoio de toda comunidade escolar. As autoridades ligadas à educação entendiam que era uma disciplina que não tinha muita importância em ser praticada pelos/as alunos/as. Para Betti e Zuliani (2002, p. 74-75) "A Educação Física deve assumir a responsabilidade de formar um cidadão capaz de posicionar-se criticamente diante das novas ideias de cultura corporal de movimento".

Baseado na informação de Betti e Zuliani (2002) entende-se que na Educação Física, os/as alunos/as não devem aprender somente os fundamentos e as regras básicas dos esportes em geral, mas também que haja entre todos/as do grupo um olhar de alteridade em relação às diferenças.

Na hora de separar os times, os meninos fizeram uma confusão, pois na turma há uma menina (aluna 2) que joga bem o futsal e todos queriam jogar com ela, dizendo que as demais não sabem nada.

Diante deste fato, é possível perceber que há um limite que tensiona as diferenças de gênero entre meninos e meninas. Dito de outra maneira, a menina que tem conhecimento e habilidade motora na modalidade de futsal e que não se aproxima do padrão que é renegado aos alunos de fragilidade, ou nas palavras deles "mole" e que "não sabem nem correr", essas serão aceitas. 
É nesse sentido que concordamos com Tiago Duque, quando ele entende que: "Contemporaneamente, quando o assunto é inteligibilidade e reconhecimento no campo de gênero e da sexualidade, não é possível afirmar onde inicia um e termina o outro" (2017, p. 127). Em outras palavras, não é possível generalizar o (não) preconceito para com as mulheres nas aulas de Educação Física, as relações de poder são sempre localizadas.

Nesta mesma aula, o aluno 2 se recusou a jogar com as meninas e preferiu não participar. A professora não conseguiu fazer com que ele entrasse na quadra, mas ela não tirou as meninas do jogo. Segundo Altman (1998), separar alunos de alunas durante as aulas de Educação Física, abre caminhos para o aumento do preconceito contra as meninas durante as aulas. A aula terminou às $10 \mathrm{hs:} 30 \mathrm{~min}$, os/as alunos/as não queriam entregar a bola, a professora então precisou retirá-la deles.

De acordo Altmann (1998), a separação sexista durante as aulas de Educação Física, abriu o caminho para que intensificasse o preconceito durante as aulas e ao mesmo tempo deixou os/as professores/as incapacitados/as de trabalharem tal situação. Talvez esse seja o real motivo pelo qual existem barreiras, ao tentarem trabalhar de forma mista na realização das atividades nas escolas. Para Altmann (1998, p. 103): "Separar meninos e meninas nas aulas é tornar as fronteiras das divisões de gênero mais rígidas do que de fato são e negar a meninas e meninos a possibilidade de cruzá-las; é furtar-Ihes de antemão a possibilidade de escolha entre estarem juntos e separados".

No segundo dia, chegamos á escola por volta de 9hs e10min, já perto do início da aula. Nesse dia estavam todos/as as/os alunos/as presentes na aula. Como era uma quinta feira, dia que teriam treinamento no período vespertino, logo que começou a aula, a coordenadora foi até a quadra avisálos que não haveria o treino. Os alunos comemoraram, então questionamos o porquê daquela reação. Alguns alunos nos relataram o seguinte: Aluno 1 "Professora, mulher não sabe jogar bola". Aluno 2 "Ela não deixa nós jogar como gostamos". Aluno 3 "Ela é muito chata". Aluno 4 "Nós não gostamos de praticar o treino nas quintas, porque é uma professora, preferimos o treino das terças-feiras, que é um professor o treinador".

Diante destes relatos, é preciso entender os esportes, não apenas como processos esportivos, mas também como um meio social que precisa ser levado em consideração, principalmente quando se reflete sobre experiências e marcadores sociais da diferença. Em outras palavras, é preciso dar devida atenção não só quando eles, os marcadores, operam em relação a produção das experiências, nos contextos escolares e esportivos.

Não muito distante da realidade dos dias de hoje, observa-se que o esporte tem sua maneira de ser generificado, evidenciando/selecionando especificidades de cada gênero para cada esporte. Wagner 
Camargo e Cláudia Kessler apontam que "os corpos de mulheres são, via de regra, inferiorizados em termos de performance e erotizados/objetificados no que diz respeito à beleza e à sensualidade" (2017, p. 193).

Altmann et al (2011) refletem acerca das habilidades motoras de meninas e meninos na prática de jogos esportivos. As autoras consideraram que as diferenças de desempenho entre alunas e alunos tem relação com a forma não crítica tanto dos alunos/as quantos dos/as professores/as em refletirem as singularidades/diferenças entre homens e mulheres. As mesmas propõem que as aulas sejam ministradas de forma coeducativa, proposta essa que questiona e aproxima as diferentes manifestações de gênero e sexualidade nas aulas.

Esses fatos confirmam o que dizem Bozi et all (2008), que quando se trata de gênero, percebemos que há um esforço por parte de algumas mulheres em resistir contra o preconceito. Fato este visivel mediante o relato acima, uma vez que a professora mesmo passando por situações de discriminação não deixa de treinar seus alunos.

Nesse mesmo dia aconteceu que o aluno 5 chutou a bola no rosto da aluna 3 com a intenção de tirá-la da quadra. Essa aluna estava no gol e ele acreditava que ela não sabia jogar bem, pois falou: "Ela não sabe segurar a bola de futsal professora!".

De acordo com André Silva e Patrícia Nazário, (2018), devido ao preconceito percebe-se uma inclinação para a violência contra a mulher na Educação Física Escolar, onde frequentemente, como no caso dos meninos chutarem uma bola forte no rosto de uma menina, não se encara como uma forma de preconceito e muito menos violência por simplesmente se tratar de crianças e adolescentes, sendo que muitos desses casos, atitudes como essas acima citadas, são passivas de omissão, sem uma intervenção via diálogo por parte de professores/as desta disciplina e pela direção da escola.

A professora investigada não se omitiu, pois conversou com o aluno 5 explicando que eles precisam aceitar os jogos mistos, mas sem atitudes que venham a machucar as colegas.

De acordo com Mauro Jesus e Fabiano Devide (2006), desenvolver as aulas mistas, não é tão fácil para os/as professores/as de Educação Física, já que os meninos trazem histórico e culturamente o conceito de serem os melhores e de terem a preferência em relação às meninas. As meninas por sua vez, entendem que elas não têm a obrigatoriedade de desenvolverem as atividades físicas propostas nas aulas.

Diante dessas dificuldades, o/a docente deve intervir de maneira a problematizar esse conceito, incentivando os/as alunos/as a desenvolverem atividades sempre juntos/as. Fazendo assim com que haja um melhor entendimento por parte dos/as alunos/as sobre a diversidade de gênero, principalmente no contexto escolar, como bem refletem Julia Silvestrin e Maria Saraiva (2013). 
O jogo foi até o final, mas esse aluno continuou a reclamar da menina no gol, falando a todo o momento "que se ela tomasse gol, iria bater nela". Mas a aluna não se importou com as falas do colega e terminou a partida no gol.

A violência recorrente nas atitudes dos/das alunos/as na escola, segundo Marilena Ristum (2002), não são advindas exclusivamente do ambiente escolar, mas também do próprio cotidiano do aluno em diversos espaços, como por exemplo, familiar e religioso.

Ao chegar ao ambiente escolar, as violências são exercidas de diferentes formas (desde a forma psicológica até a física), já que as escolas geralmente não contam com respaldo de politicas públicas para combatê-las. As escolas em grande parcela deixam uma brecha muito ampla, não mantendo profissionais para trabalharem diariamente com alunos/as violentos/as que necessitam desse tipo de acompanhamento, como discute Louro (2001).

Segundo Ristum (2002), para as/os professores/as das escolas públicas, fica evidente a impotência diante a violência durante as aulas, já que eles/as não contam com apoio ou ajuda de pessoas capacitadas para lhes orientar nessa situação.

No terceiro dia, estavam presentes 18 alunos, haviam faltado um aluno e uma aluna, as/os alunos/as já estavam mais familiarizados conosco. Esse dia foi o mais turbulento, pois eles/as estavam agitados/ as, não paravam para ouvir as orientações da professora, atrapalhando assim o começo da aula.

No momento do alongamento e aquecimento, os meninos começaram a dizer que as meninas não iriam conseguir realizar a atividade proposta pela professora, o que ocasionou muitos desentendimentos por conta deles indagarem que elas não são capazes de ir e voltar em um pé só.

O aluno 4 começou a provocar as meninas com discursos pejorativos como "gorda", "vocês não sabem nada". Este aluno já estava em atrito com a professora desde o início, pois antes de ir para a quadra comentou: "Quero permanecer na sala de aula para terminar uma atividade de português." A professora não aceitou que ele ficasse na sala e esse foi para a quadra com os demais alunos. Chegando lá, provocou muitos conflitos com a professora e aos colegas dizendo que não iria jogar futsal com meninas porque ele não é uma "marica".

Marica, bicha, mulherzinha, afeminado, viado, boiola, sapatão, mulher-macho, paraíba, são tantas as expressões para rotular, classificar, nomear de forma preconceituosa e estigmatizada as homossexualidades/lesbianidades, ao mesmo tempo em que o uso do enunciado "marica" reforça a masculinidade hegemônica fundamental para a constituição do se tornar homem em contraposição as feminilidades.

Para considerar algo normal, é preciso que imediatamente haja o seu oposto: o anormal, o antinatural, aquele ou aquilo que foge dos padrões estabelecidos histórico, social e culturalmente; dessa forma a 
homossexualidade ainda está classificada como um comportamento errôneo. A dissertação de Luiz Neto (2006) investigou a produção da masculinidade de estudantes do ensino médio, assim como em outras investigações Janice Souza (2013) e Neil Franco (2009) expõe que a Educação Física, na fala dos sujeitos discriminados aparece como a disciplina onde mais ocorrem os atos homofóbicos no contexto escolar.

Esses mesmos sujeitos, se sentem constrangidos perante as agressões a que são submetidos, os sentimentos vão desde vergonha até a vontade de abandonar os estudos. Neto (2006) descreve o caso de um aluno chamado Cleber, que ao relatar à diretoria as discriminações a que foi submetido, a ação por parte da mesma se limitou a transferir essa situação à família do referido aluno, e mais, sem nenhum trato afetivo que isso poderia gerar na forma como a família iria receber tal situação.

Tanto esse pesquisador quanto outros/as como Marcelo Rosa (2004) vem apontando as dificuldades históricas que a área da Educação Física tem com relação às questões referentes ao gênero e sexualidade. O trabalho de Rosa (2004) versou sobre a formação inicial dos professores de Educação Física e um dos principais resultados é de que a homofobia é expressa de forma sutil, velada, outras não tão veladas assim, como à ideia de que mulheres jogadoras de futebol são lésbicas e os homens que dançam são homossexuais.

Para Leandro Brito et all (2016), a sociedade delimita severamente alguns tipos de esportes que podem ser praticados por homens ou por mulheres. Essas atitudes dificultam muito as relações entre homem/mulher ou homossexual/heterossexual, nas práticas de esporte, em clubes esportivos, centro de treinamento ou escolinhas para alunos bem pequenos ainda, o que abre caminhos para que o preconceito chegue às aulas de Educação Física escolar.

Esse dia a aula não terminou na quadra no tempo de costume, a professora levou os/as alunos/as para a sala de aula faltando 15 minutos para o fim. Chegando à sala, ela conversou com toda a turma explicando que não poderia mais acontecer esse tipo de atitude. Assim os/as alunos/as escutaram em silêncio. Permanecemos na sala com a turma até o sinal.

Durante o processo de observação das aulas de Educação Física, tendo como foco o preconceito contra as mulheres na realização das atividades, percebemos que na turma investigada de alguma forma existe preconceito. Podem-se citar alguns como: a resistência dos meninos em desenvolver as atividades com as meninas, não acreditar que elas são capazes e que elas tenham força e habilidade nos esportes. Além das ofensas verbais dos alunos no intuito de humilhar e desvalorizar as alunas e professora nas aulas.

0 que nos chamou muito a atenção foi que a professora evitou com que os meninos organizassem os times deixando as meninas fora da aula. Ela trabalha de forma mista, mesmo com os meninos reclamando que as meninas não sabem ou não conseguem. Presenciamos alguns conflitos da professora com alguns 
alunos que insistiam em não participar das aulas juntos com as alunas, mas a professora resolvia de forma que elas não se sentissem prejudicadas, ou seja, não retirando-as da quadra esportiva.

A professora conseguia que todos/as participassem juntos/as das aulas práticas, mesmo com as reclamações dos alunos até o final da aula. Esses encaminhamentos também são propostos na produção acadêmica de Silvana Goellner (2015) quando a mesma investiga as relações entre gênero-mulheresesporte e a Educação Física no âmbito escolar e esportivo.

Houve um momento em que ficou explícito que os meninos têm uma conduta preconceituosa até mesmo em relação a professora, se recusando a participar dos treinos ministrados por ela que acontecem no período vespertino, pois entendem que a professora não tem conhecimento de futebol e não os deixam jogar como eles querem e isso unicamente por a mesma ser mulher.

Transgressoras ou não, as mulheres há muito, estão presentes no futebol brasileiro. Vão aos estádios, assistem campeonatos, acompanham o noticiário, treinam, fazem comentários, divulgam notícias, arbitram jogos, são técnicas, compõem equipes dirigentes... enfim, participam do universo futebolístico e isso não há como negar (GOELLNER, 2005, p. 149).

É por meio da educação que o futebol poderá ser reconhecido como um esporte para todos/as podendo contribuir para que futuramente as mulheres não sejam discriminadas pelo simples fato de jogarem futebol, ministrarem treinos, ou seja, participarem das diferentes manifestações do futebol.

\section{CONSIDERAÇõES FINAIS}

Diante dos pressupostos teóricos, considerando principalmente os dados de observações levantados nessa pesquisa, entende-se que ainda existe o preconceito de gênero, direcionados as mulheres/alunas/ professora, mesmo com ações voltadas para que atitudes preconceituosas em relação a elas não ocorram. Percebem-se que os atos preconceituosos contra as mulheres/alunas/professora estão presentes além do âmbito da Educação Física Escolar e do esporte, pois ainda estão diretamente ligados a uma questão cultural relacionado ao ambiente familiar, religioso, forma de educação dos/as filhos/as.

Em relação ao objetivo na realização do presente estudo, ficou evidente que há preconceito, não somente contra as alunas, mas também contra a professora. Mesmo enfrentando a aversão dos meninos, a professora utiliza o método de trabalho misto, durante as aulas, na realização de qualquer atividade. 
Diante das atitudes de violência e preconceito dos meninos para com as meninas, a professora interferiu de maneira profissional, com diálogos e explicações, os/as orientado no sentido de almejar uma alteridade em relação às meninas não somente dentro da escola, mas em todos os lugares.

Compete não somente ao/a professor/a de Educação Física, embora sua atuação seja de suma importância/relevância para quebrar determinados paradigmas "impostos" desde o surgimento da humanidade no que se refere às questões de gênero. Cabe a toda a comunidade escolar orientar na conscientização da discriminação contra mulheres, isto desde uma fala, um gesto ou projetos que visem trabalhar a questão da igualdade das diferenças e participação feminina em deferentes atividades de modo a terem as mesmas oportunidades que os homens no que se refere não somente à participação em atividades de cunho esportivo, mas também no que concerne à vida em sociedade: educação, trabalho e remuneração, religião, família entre outros.

Tendo em vista que a pesquisa se deu com uma turma de determinada faixa etária, seria interessante uma pesquisa que abrangesse outras faixas etárias, como a Educação Infantil e Ensino Médio.

\section{REFERÊNCIAS}

ALTMANN, Helena. Rompendo fronteiras de gêneros: Marias (e) homens na educação física.

Dissertação (Mestrado em Educação). Universidade Federal de Minas Gerais, Belo Horizonte, UFMG. 1998.

ALTMANN, Helena; AYOUB, Eliana; AMARAL, Silvia Cristina Franco. Gênero na prática docente em educação física: meninas não gostam de suar, meninos são habilidosos ao jogar? Revista de Estudos

Feministas. Florianópolis, v. 19, n. 2, p. 491-501, maio-agosto/2011.

BETTI, Mauro; ZULIANI, Luiz R. Educação física escolar: uma proposta de diretrizes pedagógicas. Revista Mackenzie de Educação Física e Esporte. Bauru, ano I, n. 1, 2002.

BONFIM, Cláudia Ramos de Souza. Desnudando a Educação Sexual. Campinas: Papirus, 2012.

BOZI, Luiz Henrique Marchesi; ESPERANÇA, Rodrigo Andrade Alvarenga; JESUS, Miranda Dayane Graciele; MELO, Ana Luiza Mota. Educação Física Escolar: Principais Formas de Preconceito Revista Digital - Buenos Aires- Ano 12-n¹17-Fevereiro de 2008. Disponível em: <http://www.efdesportes. com/efd117/educacao-fisica-escolar-principais-formas-de-preconceito.htm> Acessado em: 09 de maio 2018. 
BRITO, Leandro de Teofilo; PONTES, Vanessa Silva; PEREIRA, Erik Giuseppe Barbosa. Masculinidades queer no voleibol. Textura, Canoas, v. 18, n. 38, p. 178-194. Set. 2016.

CAMARGO, Wagner Xavier; KESSLER, Cláudia Samuel. Além do masculino/feminino: gênero, sexualidade, tecnologia e performance no esporte sob perspectiva crítica. Horizontes Antropológicos, n. 47, p. 191, 2017. Disponível em: <https://journals.openedition.org/horizontes/1488>. Acesso em: 13 ago. 2018.

CRENSHAW, Kimberle. A intersecionalidade na discriminação de raça e gênero. In: VV. AA. Cruzamento: raça e gênero. Brasília: Unifem, 2004.

DUQUE, Tiago. Gêneros Incríveis: um estudo sócio-antropológico sobre as experiências de (não) passar por homem e/ou mulher. Campo Grande: Editora UFMS, 2017.

FRANCO, Neil. A diversidade entra na escola: histórias de professores e professoras que transitam pelas fronteiras das sexualidades e do gênero. 2009. 239 f. Dissertação (Mestrado em Educação). Universidade Federal de Uberlândia, Uberlândia, 2009.

GOELLNER, Silvana Vilodre. Corpo: (Re) Pensando entendimentos, articulações e possibilidades.

Diversidade e Educação. Rio Grande, v. 1, p. 5-8, 2015.

. Mulheres e futebol no Brasil: entre sombras e visibilidades. Rev. bras. Educ. Fís. Esp. São

Paulo, v. 19, n. 2, p. 143-151, abr./jun., 2005.

GUINTHER, Hartmut - Pesquisa Qualitativa Versus Pesquisa Quantitativa: Esta É a Questão? Teoria e Pesquisa. Brasília, v. 22, n. 2, p. 201-210, mai/ago, 2006.

HOLLANDA, Aurélio Buarque Ferreira de. Novo Dicionário Aurélio da Língua Portuguesa. 4 Ed. Curitiba: Positivo, 2009.

JESUS, Mauro Louzada de; DEVIDE, Fabiano Pries. Educação física escolar, co-educação e gênero: mapeando representações de discentes. Movimento, Porto Alegre, v. 12, n. 3, p. 123-140, 2006.

LOURO, Guacira Lopes. Gênero, Sexualidade e Educação: uma perspectiva pós estruturalista. Petrópolis: Vozes, 2001.

NETO, Luiz Ramires. Habitus de gênero e experiência escolar: jovens gays no ensino médio em São Paulo. 2006. 170 f. Dissertação (Mestrado em Educação). Universidade de São Paulo, São Paulo, 2006. 
PAIM, Cristina Maria Chimelo. A responsabilidade social do professor de Educação Física frente à violência de gênero no contexto da educação física e dos esportes. In: efdesports.com. Disponivel em: <http://www.efdeportes.com/efd138/violencia-de-genero-no-contexto-da-educacao-fisica.htm>. Acesso em: 10 fev. 2018.

PRADO, Vagner Matias do; ALTMANN, Helena; RIBEIRO, Inês Arilda Miranda. Impacto pela sociedade, como normal ou natural. Currículo Sem Fronteiras. Campinas, v. 16, n. 1, p. 59-77 jan./abr., 2016. Disponivel em: <http://www.Ceap.br/material/MAT25102010170018.pdf>.

RISTUM, Marilena. Violência urbana: a avaliação de professoras sobre a atuação da escola. Psicol. esc. educ., Campinas, v. 6, n. 2, p. 167-176, dez. 2002. Disponível em: <http://pepsic.bvsalud.org/scielo. php?script=sci_arttext\&pid=S1413-85572002000200007\&Ing=pt\&nrm=iso >. Acesso em: 24 maio 2018.

SANTOS, Manoel José dos. As relações de gênero e a educação física escolar: desafios pedagógicos. Trabalho de Curso (Licenciatura em Educação Física) - Faculdade de Ensino Superior Dom Bosco, Cornélio Procópio (PR), 2012.

SILVA, André Luiz dos Santos; NAZARIO, Patrícia Andrioli. Mulheres atletas de futsal: estratégias de resistência e permanência no esporte. Rev. Estud. Fem., Florianópolis, v. 26, n. 1, 2018. Disponível em <http://www.scielo.br/scielo. php?script=sci_arttext\&pid=S0104-026X2018000100700\&lng=pt\&n rm=iso>. Acesso em 24 maio 2018.

SILVESTRIN, Julia Mara Pegoraro; SARAIVA, Maria do Carmo. O debate de gênero nas propostas curriculares da Educação Física na Educação básica dos estados do Paraná e do Rio Grande do Sul.

Revista Pedagógica (Unochapecó. Online), v. 15, p. 391-414, 2013.

SOUZA, Janice Aparecida de. Estratégias de escolarização de homossexuais com sucesso acadêmico. 2013. 113 f. Dissertação (Mestrado em Educação). Universidade Federal de Minas Gerais, Belo Horizonte, 2013.

ZAMBONI, Marcio. Marcadores sociais da diferença. Sociologia: grandes temas do conhecimento (Especial Desigualdades), São Paulo, v. 1, p. 14-18, 01 ago. 2014. 